\title{
Improved Serial Sectioning Techniques for Correlative Light-Electron Microscopy Mapping of Human Langerhans Islets
}

\author{
Sei Saitoh ${ }^{1,2}$, Nobuhiko Ohno ${ }^{1}$, Yurika Saitoh ${ }^{1}$, Nobuo Terada ${ }^{1,3}$, Satoshi Shimo ${ }^{1}$, \\ Kaoru Aida ${ }^{4}$, Hideki Fujiii ${ }^{5}$, Tetsuro Kobayashi ${ }^{4}$ and Shinichi Ohno ${ }^{1}$ \\ ${ }^{1}$ Department of Anatomy and Molecular Histology, Interdisciplinary Graduate School of Medicine and Engineering, \\ University of Yamanashi, 1110 Shimokato, Chuo, Yamanashi 409-3898, Japan, ${ }^{2}$ Present address: Section of Electron \\ Microscopy, Supportive Center for Brain Research, National Institute for Physiological Sciences, Okazaki 444-8787, \\ Japan, ${ }^{3}$ Department of Occupational Therapy, School of Health Sciences, Shinshu University School of Medicine, \\ 3-1-1 Asahi, Matsumoto, Nagano 390-8621, Japan, ${ }^{4}$ Third Department of Internal Medicine, Interdisciplinary Graduate \\ School of Medicine and Engineering, University of Yamanashi, 1110 Shimokato, Chuo, Yamanashi 409-3898, Japan \\ and ${ }^{5}$ First Department of Surgery, Interdisciplinary Graduate School of Medicine and Engineering, University of \\ Yamanashi, 1110 Shimokato, Chuo, Yamanashi 409-3898, Japan
}

Received July 24, 2017; accepted November 29, 2017; published online February 21, 2018

\begin{abstract}
Combined analysis of immunostaining for various biological molecules coupled with investigations of ultrastructural features of individual cells is a powerful approach for studies of cellular functions in normal and pathological conditions. However, weak antigenicity of tissues fixed by conventional methods poses a problem for immunoassays. This study introduces a method of correlative light and electron microscopy imaging of the same endocrine cells of compact and diffuse islets from human pancreatic tissue specimens. The method utilizes serial sections obtained from Epon-embedded specimens fixed with glutaraldehyde and osmium tetroxide. Double-immunofluorescence staining of thick Epon sections for endocrine hormones (insulin and glucagon) and regenerating islet-derived gene 1 a (REG1a) was performed following the removal of Epoxy resin with sodium ethoxide, antigen retrieval by autoclaving, and de-osmification treatment with hydrogen peroxide. The immunofluorescence images of endocrine cells were superimposed with the electron microscopy images of the same cells obtained from serial ultrathin sections. Immunofluorescence images showed well-preserved secretory granules in endocrine cells, whereas electron microscopy observations demonstrated corresponding secretory granules and intracellular organelles in the same cells. In conclusion, the correlative imaging approach developed by us may be useful for examining ultrastructural features in combination with immunolocalisation of endocrine hormones in the same human pancreatic islets.
\end{abstract}

Key words: correlative microscopy, Epon-embedded, compact and diffuse islets, immunostaining, hormone

Correspondence to: Sei Saitoh, M.D., Ph.D., Section of Electron Microscopy, Supportive Center for Brain Research, National Institute for Physiological Sciences, Okazaki 444-8787, Japan.

E-mail: saitoh@nips.ac.jp

\section{Introduction}

A large number of endocrine cells, constituting $1-2 \%$ of the total volume of the human pancreas in adults, are distributed in more than one million islets of Langerhans, first described by Paul Langerhans in 1869. The pancreatic 
islets, in turn, are distributed throughout the pancreas at variable densities in different lobules, although the density in the tail portion is usually slightly higher [44]. Pancreatic islet endocrine stem cells differentiated to mature islet endocrine cells produce four major peptide hormones: insulin ( $\beta$-cell granule), glucagon ( $\alpha$-cell granule), somatostatin $(\delta$-cell granule), and pancreatic polypeptide (PP-cell granule), all of which show specific views by electron microscopy $[8,9,27]$. Human and rodent pancreas are developed from two different embryological origins; the dorsal origin develops the body and tail portions, whereas the ventral origin derives the head portion of the pancreas. The majority of the pancreas is derived from the dorsal anlage $[8,21,27$, $31,38]$. The islets can be classified into two types [27]. "Compact" islets comprise the majority $(90 \%)$; they are covered by nests of connective tissues. Compact islets are composed of trabeculae of endocrine cells interspersed with clear capsules between adjacent pancreatic exocrine acini [17]. Other islets are "diffuse"; they have no nests separating them from adjacent exocrine acini. However, the ultrastructure supporting "diffuse" pancreatic islets including islet-encapsulating basement membranes, extracellular matrix, and adjacent exocrine acini, have not been elucidated in detail $[1,5,6,16,27]$. Regenerating islet-derived gene 1 alpha (REG1 $\alpha$ ) is secreted by the exocrine pancreas or $\beta$ cells and affects islet cell regeneration [40, 42], thereby regulating the development of Langerhans islet architecture and diabetogenesis $[1,13,46]$.

Conventional histochemical methods, such as aldehyde-fuchsin staining, Hellerstrom-Hellman silver staining, and immunohistochemical labelling of peptide hormones, are currently the major approaches used with light microscopy to directly distinguish between types of endocrine cells [10,24]. Although examination of multiple peptide contents in combination with investigation of the ultrastructural features of individual endocrine cells would provide a detailed analyses of physiological and pathological alterations of pancreatic islets in genetically and epigenetically divergent samples such as human tissues, correlative light and electron microscopy observations combined with double-immunostaining using fluorescentlylabelled secondary antibodies in the same Epon-embedded sample is an improved technique for correlative lightelectron microscopy mapping which has been described before $[2,3,23,29,43]$.

In the present study, we utilised serial sections of Epon-embedded pancreatic tissues, fixed routinely with glutaraldehyde and $\mathrm{OsO}_{4}$, for observations with transmission electron microscopy and light microscopy following double immunofluorescence staining of endocrine cells for insulin and glucagon or for insulin and REG1 $\alpha$. Our results demonstrate that routinely prepared Epon-embedded samples can be utilised for correlative imaging, which allows the combined examination of ultrastructural features and the determination of endocrine hormone localisation by an immunocytochemical method in the same human endocrine cells. In this study, we focused on human heterogeneous endocrine cells found in diffuse islets immunolocalized with insulin and either glucagon or REG1 $\alpha$.

Finally, we confirmed the three-dimensional architecture of compact islets (tail) and diffuse islets (head) of pancreas from normal adult C57BL/6J mice by SBF-SEM [35].

\section{Materials and Methods}

\section{Tissue samples}

Human pancreatic tissue samples from five patients with gastric carcinoma were obtained during pancreatic resection in surgical operating rooms.

Two male C57BL/6J mice at 20 weeks of age were purchased from Charles River (Yokohama, Japan) and housed with free access to food and water, under pentobarbital anaesthesia. Pancreatic tissues obtained from both animals were taken from two different portions (head and tail).

\section{Ethics}

The Ethics Committee of the University of Yamanashi approved all the procedures performed in the present study. All patients gave their written informed consent for the collection and examination of the resected pancreas samples.

All animal experiments were approved by the Institutional Animal Care and Use Committee of National Institute for Physiological Sciences, and were performed in accordance with relevant guidelines and regulations including the "Principles of laboratory animal care" (NIH publication No. 85-23, revised 1985).

\section{Tissue preparation for transmission electron microscopy (TEM)}

Small pieces of human and mouse pancreatic tissue were prefixed with $2.5 \%$ glutaraldehyde in $0.1 \mathrm{M}$ phosphate buffer (PB; $\mathrm{pH} 7.4$ ) for $1 \mathrm{hr}$ and post-fixed with $1 \%$ osmium tetroxide in $0.1 \mathrm{M}$ PB for $1 \mathrm{hr}$. The specimens were routinely dehydrated by passing the tissue through a series of solutions with increasing ethanol concentrations and then embedded in Epon 812 epoxy resin. To examine the specimens, thick Epon sections were first cut at $0.5-\mu \mathrm{m}$ thickness and routinely stained with toluidine blue (TB). These sections were checked and trimmed to visualise Langerhans islets during the next step. Then, ultrathin sections were cut at 70-80-nm thickness with a diamond knife on an ultramicrotome and mounted on $\Phi 1 \times 2 \mathrm{~mm}$ single slit copper grids with a formvar film covered by evaporated carbon (Fig. 1A). Then, serial $0.5-\mu \mathrm{m}$ thick sections were cut and put on MAS-coated glass slides (Matsunami Adhesive Slides, Matsunami Glass, Osaka, Japan) for subsequent immunohistochemical staining (Fig. 1B). The ultrathin sections of human pancreas tissues on copper grids were double-stained with uranyl acetate and lead citrate and finally, observed under a H-7500 transmission electron microscope (Hitachi, Tokyo, Japan) at an accelerating volt- 


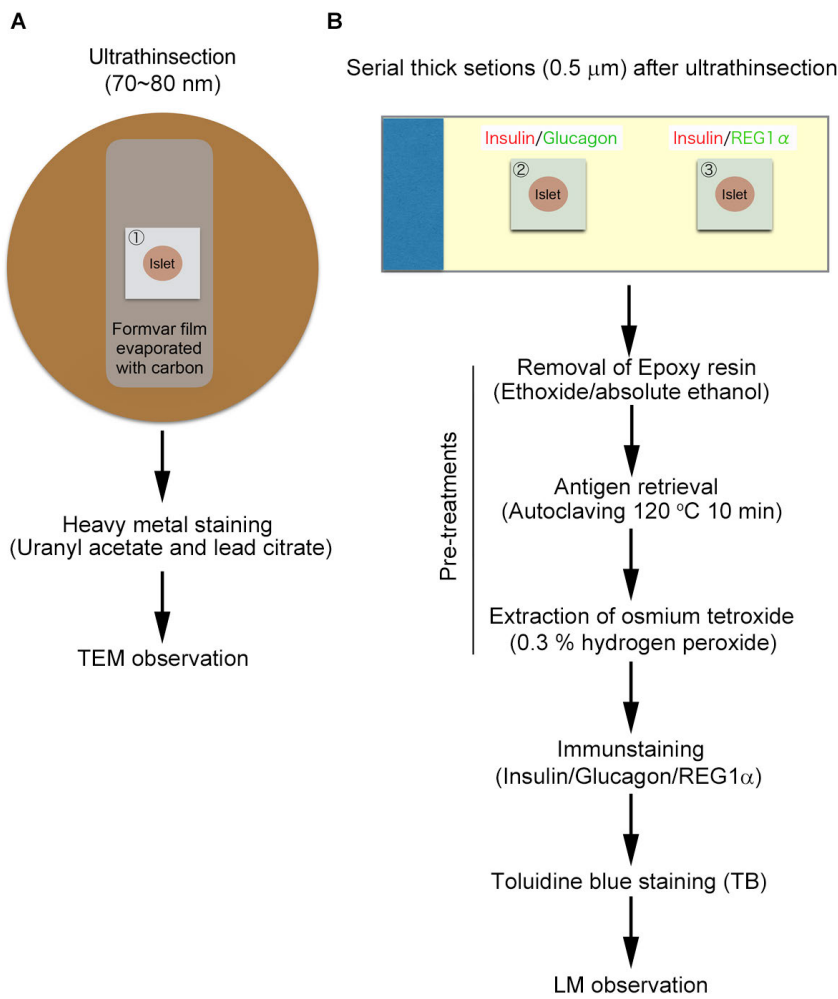

Fig. 1. Schematic representation of serial sectioning techniques for correlative light-electron microscopy mapping of human Langerhans islets. A: Schematic images illustrating an ultrathin section of a Langerhans islet mounted on a $\Phi 1 \times 2 \mathrm{~mm}$ single slit copper grid with a formvar film covered by evaporated carbon. B: Flow chart of pre-treatments and immunohistochemical staining procedures applied to serial thick sections after ultrathin sectioning of Epon blocks.

age of $80 \mathrm{kV}$. Electron microscopy images and montages of Langerhans islets were edited by Photoshop imaging software (Adobe Systems Incorporated, San Jose, CA, USA).

\section{Immunohistochemistry in serial thick sections of Epon blocks}

The $0.5-\mu \mathrm{m}$ thick Epon sections on MAS-coated glass slides were placed on a heating plate and heated to 60 $80^{\circ} \mathrm{C}$ for $15 \mathrm{~min}$. Epoxy resin was then removed from the sections by treatment with a mixture of ethoxide and absolute ethanol $(1: 2 ; \mathrm{v} / \mathrm{v})$ for $30 \mathrm{~min}$, washed in pure ethanol, and rehydrated in phosphate-buffered saline (PBS, $\mathrm{pH}$ 7.4). Prior to using the ethoxide/absolute ethanol mixture, saturated sodium ethoxide was aged for approximately 2 weeks until it turned dark brown [2]. Next, the specimens underwent two optional pre-treatments. For antigen retrieval pre-treatment, the specimens were autoclaved in $10 \mathrm{mM}$ sodium citrate buffer $(\mathrm{pH} 6.0)$ at $120^{\circ} \mathrm{C}$ for $10 \mathrm{~min}$ and rinsed in PBS. In addition, to extract osmium tetroxide, the specimens were placed in $0.3 \%$ hydrogen peroxide for 10 min and rinsed in PBS.

For immunoperoxidase-3,3'-diaminobenzidine (DAB) staining, the specimens were treated with $3 \%$ fish gelatin (Sigma-Aldrich, St. Louis, MO, USA) in PBS for $10 \mathrm{~min}$, followed by incubation with a guinea pig polyclonal anti-human insulin antibody (1:500-800) (A0564, Dako, Carpinteria, CA, USA), a rabbit polyclonal anti-human REG1 alpha antibody (1:200-500) (ab47099, Abcam, Cambridge, UK), or a rabbit polyclonal anti-human glucagon antibody (1:300-800) (A0565, Dako) in PBS at $4^{\circ} \mathrm{C}$ overnight. Immunocontrols were performed using the same procedure with the exception that incubation with the primary antibody was omitted.

The specimens were then incubated with a horseradish peroxidase (HRP)-conjugated rabbit anti-guinea pig IgG $(\mathrm{H}$ $+\mathrm{L})$ antibody $(1: 400)$ or a goat anti-rabbit $\operatorname{IgG}(\mathrm{H}+\mathrm{L})$ antibody (1:400; Vector Laboratories, Burlingame, CA, USA) in PBS for $1 \mathrm{hr}$ and visualised by exposure to metalenhanced DAB (Pierce, Rockford, IL, USA) for $5 \mathrm{~min}$. Finally, the specimens were incubated in $0.04 \%$ osmium tetroxide in $0.1 \mathrm{M}$ PB for $30 \mathrm{sec}$ to enhance contrast of the $\mathrm{DAB}$ reaction products.

For single- or double-fluorescence immunostaining experiments, de-osmified thick sections were treated with $3 \%$ fish gelatin in PBS for $10 \mathrm{~min}$, followed by a guinea pig polyclonal anti-human insulin antibody $(1: 400)$ and/or a rabbit polyclonal anti-human glucagon antibody (1:400), and a rabbit polyclonal anti-human REG1 alpha antibody $(1: 300)$ and/or an anti-human insulin antibody $(1: 400)$ in PBS at $4^{\circ} \mathrm{C}$ overnight. Immunocontrols were performed using the same procedure with the exception that incubation with the primary antibody was omitted.

As secondary fluorescently-labelled antibodies, we used Alexa Fluor ${ }^{\circledR} 594$ FluoroNanogold $^{\mathrm{TM}}$ goat anti-guinea pig Fab' (1:400) (Nanoprobes, Inc., Yaphank, NY, USA) and Alexa Fluor 488-conjugated donkey anti-rabbit IgG antibodies (1:400) (Life Technologies Co., Carlsbad, CA, USA). Immunostained sections were sealed with Vectashield mounting medium (Vector Laboratories). Fluorescence signals for Alexa Fluor 488 or Alexa Fluor 594 were observed with a BX-61 fluorescence microscope (Olympus, Tokyo, Japan). After obtaining fluorescence images, some thick sections were additionally stained with TB for reexamination of morphology (Fig. 1B).

\section{Tissue preparation and observation for serial block-face scanning electron microscopy (SBF-SEM)}

Samples for SBF-SEM observations were post-fixed with osmium and stained en bloc, as described previously [30]. Briefly, mouse pancreatic tissues were prefixed with $2.5 \%$ glutaraldehyde in $0.1 \mathrm{M}$ phosphate buffer ( $\mathrm{PB} ; \mathrm{pH}$ 7.4) overnight and tissues were washed with cacodylate buffer ( $\mathrm{pH}$ 7.4). Tissues were then treated with $2 \% \mathrm{OsO}_{4}$ (Nisshin EM, Tokyo, Japan) in $0.1 \mathrm{M}$ cacodylate buffer containing $0.15 \% \mathrm{~K}_{4}\left[\mathrm{Fe}(\mathrm{CN})_{6}\right]$ (Nacalai Tesque, Kyoto, Japan) for $1 \mathrm{hr}$ on ice, and $0.1 \%$ thiocarbohydrazide (SigmaAldrich) for $20 \mathrm{~min}$ and $2 \% \mathrm{OsO}_{4}$ for $30 \mathrm{~min}$ at room temperature. Thereafter, the tissues were treated with $2 \%$ uranyl acetate at $37^{\circ} \mathrm{C}$ for $3 \mathrm{hr}$. Tissues were then treated with lead aspartate solution at $60^{\circ} \mathrm{C}$ for $30 \mathrm{~min}$. The 

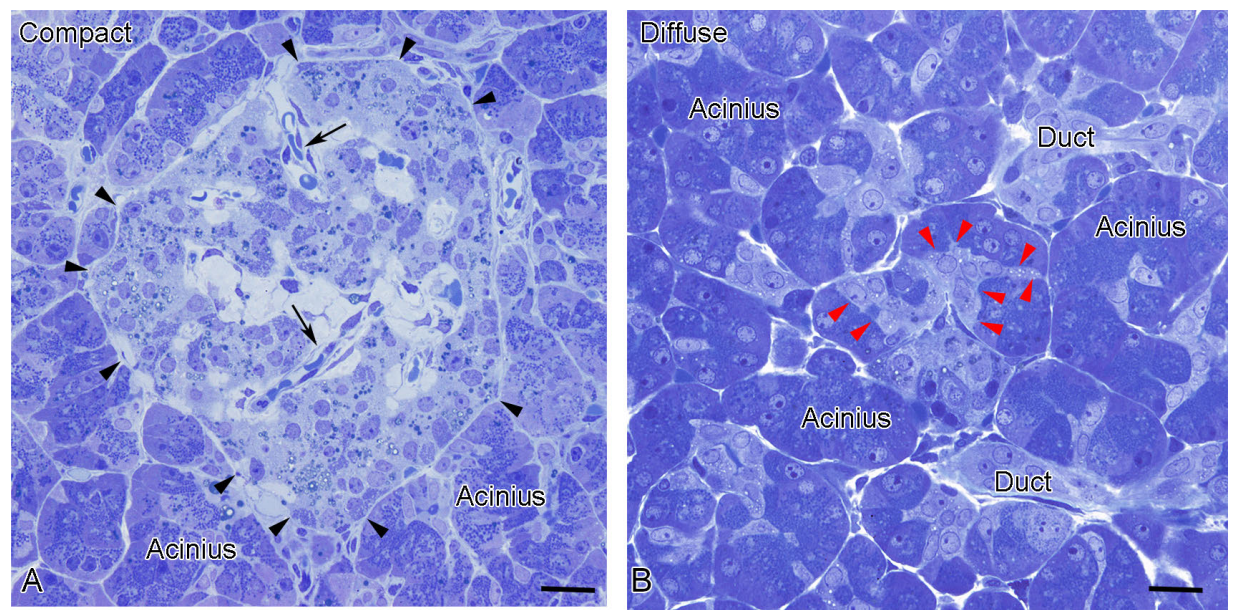

Fig. 2. Differences between compact and diffuse islets in human pancreas revealed by light microscopy observations of toluidine blue stained thick sections routinely embedded in Epon. A: The compact islet appears round to oval and is composed of endocrine cells surrounded with a capsule of connective tissue (black arrowheads). Blood capillaries (black arrows) separate the islet into several lobules. Endocrine cells have moderately light cytoplasm. B: The diffuse islet is composed of a mass of endocrine cells interspersed between adjacent exocrine acinar-like cell clusters without a clear capsule (red arrowheads) in structures that appear like acinar ducts. Bars $=20 \mu \mathrm{m}$.

specimens were routinely dehydrated by passing the tissue through a series of solutions with increasing ethanol concentrations, infiltrated with acetone dehydrated with a molecular sieve, a 1:1 mixture of resin and acetone, and $100 \%$ resin and then embedded in Epon 812 epoxy resin with carbon (ketjen black) at $60^{\circ} \mathrm{C}$ for 3 days/overnight. Following trimming of islets from mouse pancreas, samples were imaged with a Sigma ${ }^{\mathrm{TM}} \mathrm{VP}$ (Carl Zeiss, Munich, Germany) equipped with 3View (Gatan Inc., Pleasanton, CA, USA). The serial images of SBF-SEM were handled with Fiji/ImageJ, and segmented and reconstructed to 3D images using MIB (http://mib.helsinki.fi/) and Amira software.

\section{Results}

To identify compact and diffuse Langerhans islets, Epon sections of human pancreas were prepared, routinely fixed with glutaraldehyde and $\mathrm{OsO}_{4}$, stained with $\mathrm{TB}$, and observed with a light microscope (Fig. 2). The compact islets were revealed as large collections of endocrine cells having round to oval shapes (Fig. 2A, black arrowheads). Their nuclei have homogeneous chromatin patterns with nucleoli, and the cells have moderately light cytoplasm. In contrast, diffuse islets were composed of trabeculae of endocrine cells interspersed between adjacent acini (Fig. 2B, red arrowheads).

During immunohistochemical staining of the peptide hormones (insulin and glucagon) and REG1 $\alpha$, we noted that two pre-treatments after the removal of Epoxy resin (Fig. 1B), including antigen retrieval by autoclaving and extraction of osmium tetroxide with hydrogen peroxide, strongly increased specific staining for endocrine peptides and decreased non-specific background in the thick Epon sections (Figs. 3 and 5). The immunoreactivity of the HRPDAB reaction was dramatically enhanced by autoclave treatment, and the effect was more prominent in insulin immunostaining (Fig. 3D and E, insets; arrows) than in glucagon immunostaining (Fig. 3F and G, insets; arrows). Immunocontrols not incubated with primary antibodies have reduced backgrounds caused by secondary antibody conjugated-HRP-DAB reaction products and osmification (Fig. 3B and C).

The use of our modified immunostaining protocol allowed clear observations of the ultrastructure of endocrine cells immunopositive for insulin, glucagon, and REG1 $\alpha$ in serial thick and ultrathin sections in compact Langerhans islets of human pancreatic tissue (Fig. 4). Immunostaining signals for insulin in $\beta$ cell granules and for glucagon in $\alpha$ cell granules did not colocalize in the islet cells (Fig. 4A, D-F), while patterns of immunostaining for insulin and REG1 $\alpha$ overlapped in large parts of doubleimmunopositive endocrine cells (Fig. 4G-I). Immunopositive staining for insulin and glucagon was positive for most islet areas whose ultrastructures were determined in serial ultrathin sections of the same islet (Fig. 4A, D-F, J, and K). The compact islet illustrated in Fig. 4 had a higher ratio of cells positive for glucagon or insulin compared to cells from the compact islets shown in Fig. 3. Areas of $\alpha$ or $\beta$ cells on electron microscopy images were almost completely identical to the areas immunopositive for insulin and glucagon (Fig. 4A, D-F, J, and K). These correlative observations revealed that islet cells with low and high immunoreactivity for glucagon included round-shaped granules with low and high electron density (Fig. 4P-R; blue arrows), whereas insulin-positive cells with $\beta$ cell granules (Fig. 4O; red arrows) and condensing vacuoles (Fig. 4O, white arrows). Immunocontrols that were not 

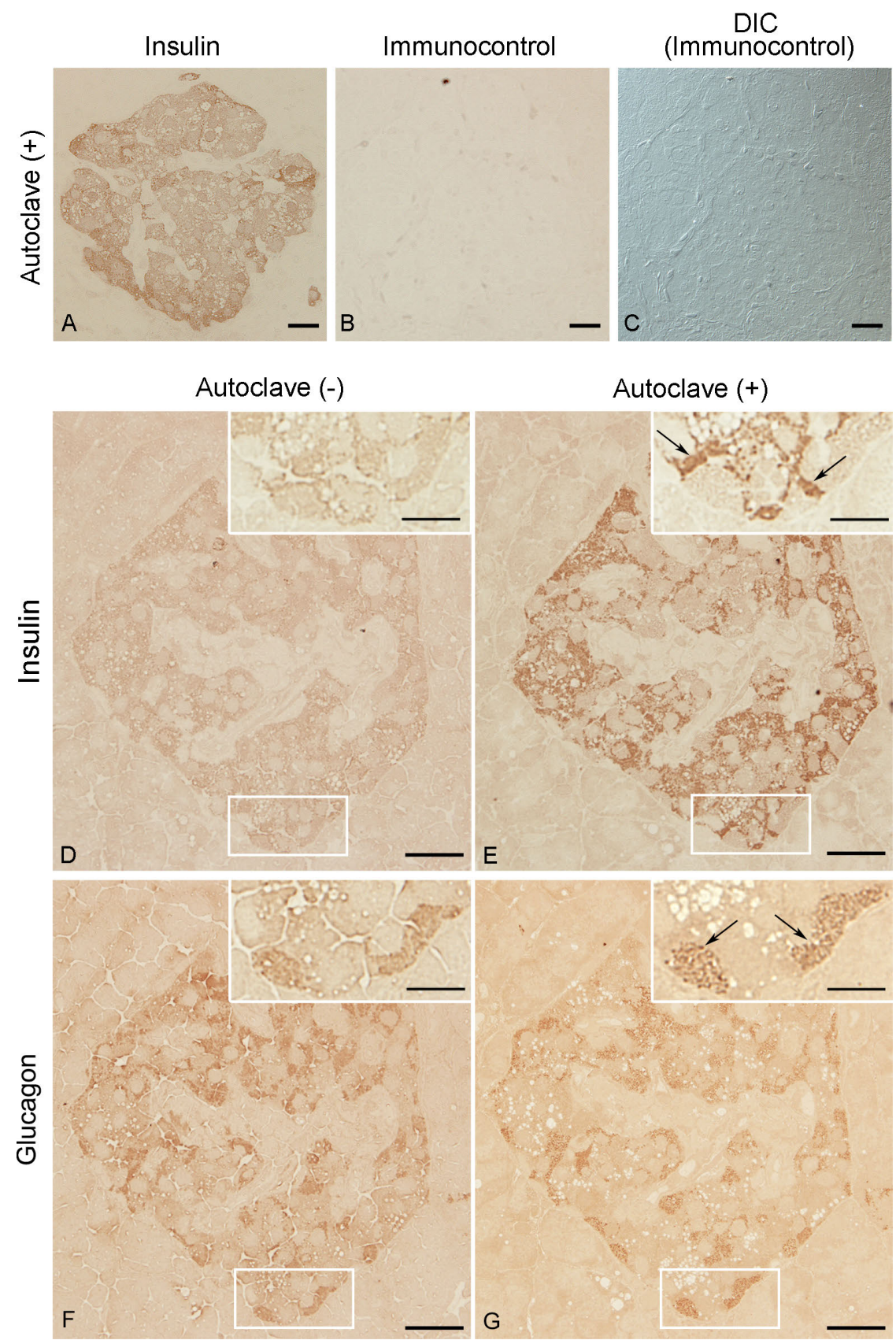

Fig. 3. Enhancement of immunostaining for insulin and glucagon in serial thick sections of a typical compact human pancreatic islet by autoclave treatment. A: Insulin-positive staining in a section that underwent autoclave treatment (AC). B: Immunocontrol incubated with secondary antibody without the primary antibody. C: Differential interference contrast microscope (DIC) image of the immunocontrol section. D: Weak insulin immunoreactivity in an untreated section. E: Stronger insulin immunoreactivity in a section that underwent AC-tiny granular patterns are more clearly detected throughout the cytoplasm of $\beta$ cells (inset, arrows). F: Improved immunoreactivity for glucagon in the cytoplasm of cells in an untreated section. G: Clear granular pattern of immunoreactivity for glucagon in a section that underwent AC (inset, arrows). Bars $=20 \mu \mathrm{m}(\mathbf{A}-\mathbf{G}) ; 10 \mu \mathrm{m}(\mathbf{D}-\mathbf{G}$, insets).

incubated with primary antibodies have less background related to the secondary antibodies conjugated-Alexia 488 and 594, and in particular, because of secondary antibody cross-reactivity to native human immunoglobulins trapped in pancreas tissues around blood vessels and fixative autofluorescence.
Immunoreactive staining for insulin and glucagon was also clearly observed in endocrine cells of diffuse islets, while exocrine cells of adjacent glandular acini were not immunostained (Figs. 5 and 6). The immunoreactivities for REG1 $\alpha$ and insulin showed different distributions in the same endocrine cells in serial thin sections of diffuse islets 

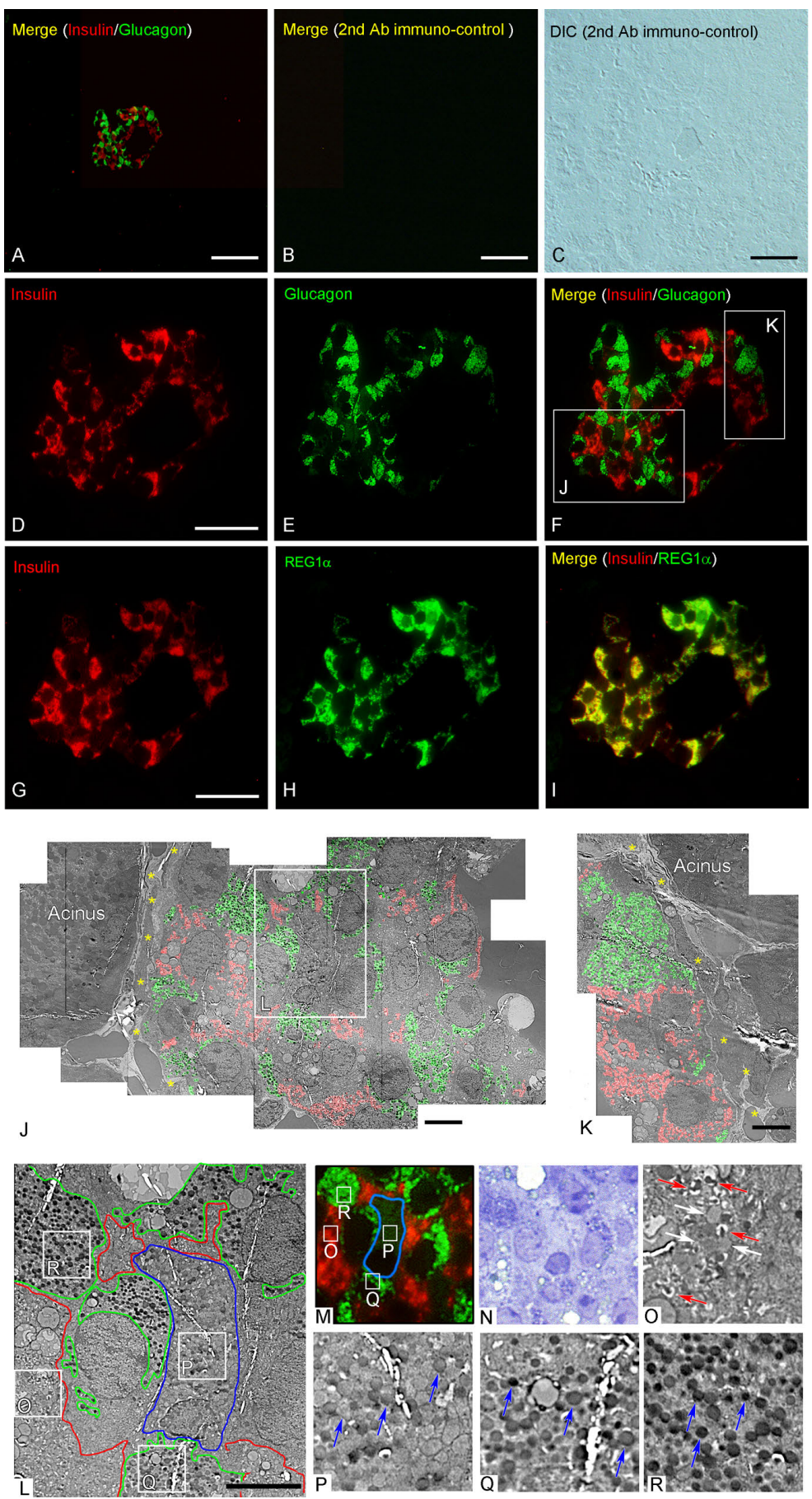

Fig. 4. Correlative light-electron microscopy mapping of a compact islet using serial Epon sections from a human pancreatic tissue specimen. Ultrastructural observations and double-immunofluorescence staining for insulin, glucagon, and REG1 $\alpha$ were carried out. A: Merged image of insulin and glucagon positive staining. B: Merged image of immunocontrol (red and green) exposed to two secondary antibodies without primary antibodies. C: Differential interference contrast microscope (DIC) image of immunocontrol section shown in (B). Islet cells with granular immunopositive staining for insulin (A, D, F, G, I, red) are immunopositive for REG1 $\alpha(\mathbf{H}, \mathbf{I}$, green), but not for glucagon $(\mathbf{A}, \mathbf{E}, \mathbf{F}$, green), whereas the immunostaining patterns of insulin and REG1 $\alpha$ largely overlap (I, yellow). Electron microscopic montages $(\mathbf{J}, \mathbf{K})$ obtained from the same field of the serial section shown in $(\mathbf{F})$. The magnified image $(\mathbf{J}, \mathbf{K})$ corresponds to the white boxes in $(\mathbf{F})$. The compact islet has a capsule of connective tissue (J, K, yellow asterisks). Mapping images of $\beta$ cell granules $(\mathbf{J}, \mathbf{K}$, pseudo-coloured red) and $\alpha$ cell granules ( $\mathbf{J}, \mathbf{K}$, pseudo-coloured green) manually coloured by Photoshop. Distribution patterns of insulin- (red) and glucagon-positive (green) cells (A, D-F) are clearly identified in the electron micrographs (J, K). Highly magnified electron microscopy images $(\mathbf{O}-\mathbf{R})$ correspond to the white boxes in $(\mathbf{L})$ and double-immunopositive staining images $(\mathbf{M})$. $\mathbf{N}$ : Toluidine blue staining for the same section $(\mathbf{F})$ of insulin-positive cells $(\mathbf{M}$, red) included $\beta$-cell granules $(\mathbf{O}$, red arrows) and condensing vacuoles $(\mathbf{O}$, white arrows), while glucagon-positive cells ( $\mathbf{M}$, green) included small numbers of round-shaped granules with low (P, blue arrows), with intermediate ( $\mathbf{Q}$, blue arrows) and high (R, blue arrows) electron densities. Bars $=20 \mu \mathrm{m}(\mathbf{A}-\mathbf{D}, \mathbf{G}) ; 1 \mu \mathrm{m}(\mathbf{J}-\mathbf{L})$. 

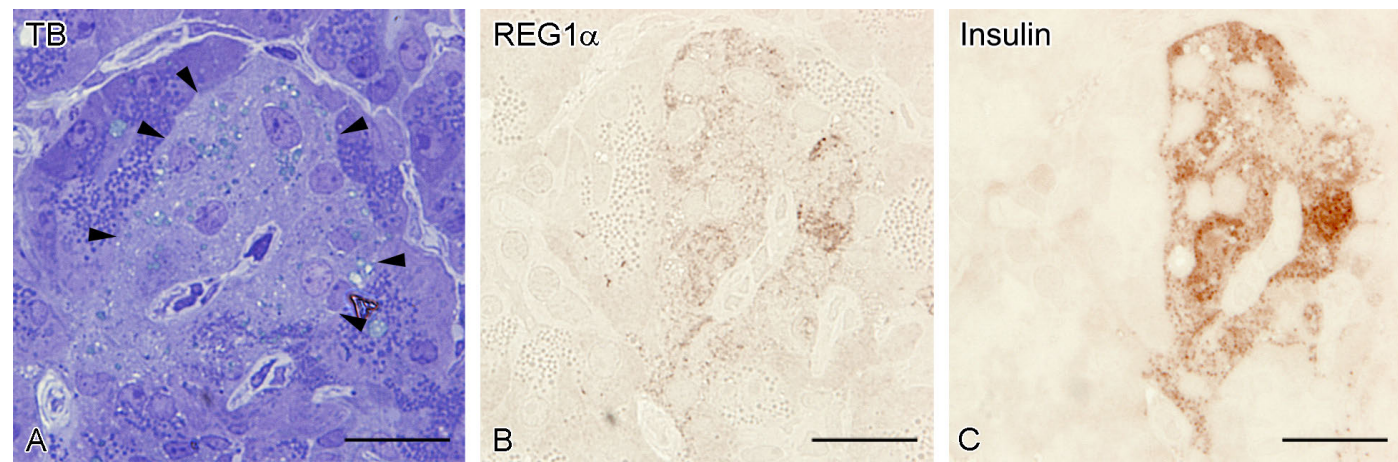

Fig. 5. Different distribution of HRP-DAB-immunoreaction products for REG1 $\alpha$ and insulin in the same endocrine cells of diffuse type islet in serial thick sections of a diffuse human pancreatic islet. The diffuse islet is composed of a mass of endocrine cells interspersed between adjacent exocrine acinar-like cell clusters without a clear capsule (A, arrowheads). Islet endocrine cells show granular immunopositive staining for REG1 $\alpha$ (B) or insulin (C), while acinar-like cells in contact with islet endocrine cells were not immunostained. TB: toluidine blue staining. Bars $=20 \mu \mathrm{m}$.

(Fig. 5B and C). Fluorescently immunostained sections were subsequently stained with $\mathrm{TB}$, and islet structures were found to be well preserved following doublefluorescence immunostaining (Fig. 6G and H). Electron microscopy observations of serial ultrathin sections were performed to reveal structural details of diffuse islets in addition to identifying the hormones produced by the respective cells (Fig. 6). It was found that $\beta$ cells double positive for REG1 $\alpha$ and insulin were also the cells that exhibited zymogen-like condensing vacuoles $(200-500 \mathrm{~nm}$ in size) and many organelles, such as mitochondria, Golgi apparatus, endoplasmic reticulum (ER), and lipofuscin granules (Fig. 6J and L, white arrows) [14]. In addition, these endocrine cell granules in contact with exocrine acinar-like cell clusters have electron-dense cores and clear halos. However, insulin and REG1 $\alpha$ double-positive endocrine cells consisted of several granular morphologies of human islet endocrine cells. We classified the granules of human islets into four types $(\alpha-, \beta-, \delta$-, and PP-cell granules) as described previously $[7,8,27,34,36]$, where (I) $\alpha$ cell type (glucagon-secretory): electron-dense without a clear halo occasionally presenting with a grey halo (Fig. $6 \mathrm{~K}$, red arrowheads); (II) $\beta$-cell type (insulin secretory): granules of this type have electron-dense cores with a crystalline shape (Fig. 6K-N, blue arrowheads); (III) $\delta$-cell type (somatostatin secretary): larger and electron-opaque (Fig. 6K, L, and N, cyan arrowheads); and (IV) PP-secretory cell type: spherical and smaller granules with a small halo (Fig. $6 \mathrm{~L}$, green arrowheads). Interestingly, islet endocrine cells in contact with adjacent exocrine acinar-like cell clusters (ATLANTIS) contained zymogen-like granules (Fig. 6M, yellow arrow), and cell-to-cell contacts were also detected (Fig. 6N, white arrows).

Finally, we examined the three-dimensional architecture of compact islets (tail) and diffuse islets (head) of pancreas from adult C57BL/6J mice by SBF-SEM (Fig. 7). Endocrine cells from diffuse islets were also in contact with adjacent exocrine acinar-like cell clusters (ATLANTIS) without a clear capsule (Fig. 7D-I). The morphologies of granules in endocrine cells of diffuse islets (Fig. 7F) mainly consisted of three types: (I) granules with a spherical dense core and a small halo similar to PP-cell granules (Fig. 7F, green arrowheads), (II) granules with a low electron-dense core without halo similar to $\delta$-cell granules (Fig. 7F, cyan arrowheads), and (III) granules with a spherical or crystalshaped dense core with a clear halo similar to $\beta$-cell granules [35]. We also found on serial SBF-SEM images that zymogen-like granules are broadly distributed in these endocrine islet cells in contact with acinar-like cells. The zymogen-like granules have an isotropic distribution from ATLANTIS to the islet cells through direct contact with lamellar ERs in diffuse islets of the pancreatic head portion in adult normal mice derived from ventral origins (Fig. $7 \mathrm{G}-\mathrm{I})$.

\section{Discussion}

In the present study, by combining etching of hydrophobic Epon with preliminary autoclaving and exposure to hydrogen peroxide, we developed a technique that allows the simultaneous analysis of cellular ultrastructure and localisation of endocrine peptides in human pancreas samples.

Combined analyses using immunohistochemical localisation of hormones and ultrastructure of endocrine cells in animal pituitary glands have been previously reported [2]. In those studies, to achieve simultaneous examination, Epon thick sections were prepared from tissues fixed with glutaraldehyde and $\mathrm{OsO}_{4}$ and peroxidase-DAB immunostaining was used for light microscopy, while electron microscopic observations were carried out in serial ultrathin sections [2]. Conventional double fixation was useful because lipid membranes, such as the plasma membrane of cells and vesicles, are well preserved. Epon-embedded sections are frequently used for ultrastructural analyses by electron microscopy because they exhibit well-preserved tissue morphology. However, the weak tissue antigenicity of Epon-embedded sections poses a problem for immuno- 

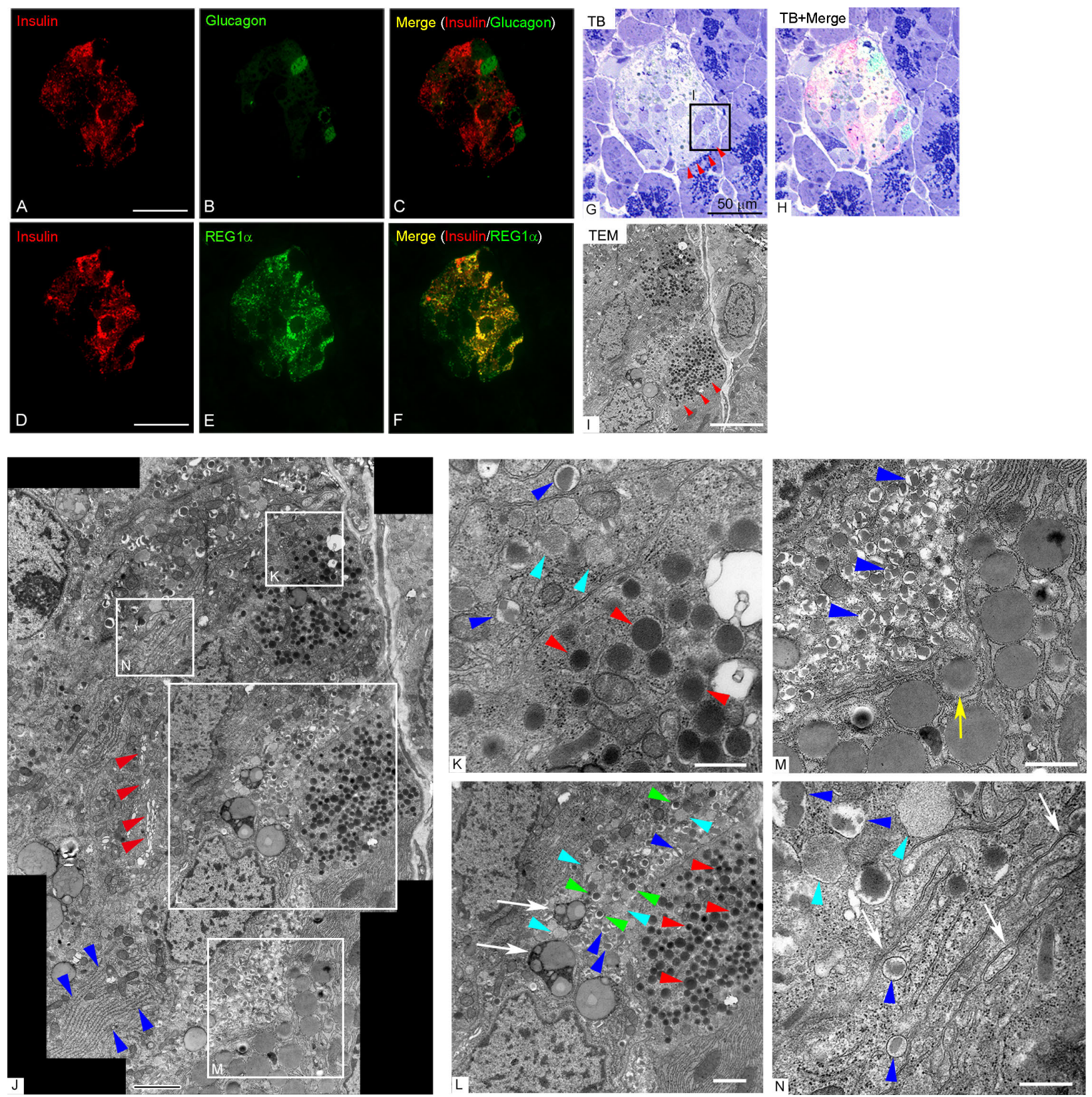

Fig. 6. Correlative light-electron microscopy mapping of a diffuse islet using serial Epon sections from a human pancreatic tissue specimen. Ultrastructural observation and double-immunofluorescence staining for insulin, glucagon, and REG1 $\alpha$ were carried out. Granular immunoreactivities for insulin $(\mathbf{A}, \mathbf{C}$, red) and glucagon $(\mathbf{B}, \mathbf{C}$, green) are sparse and dense respectively, while the immunostaining patterns of insulin $(\mathbf{D}, \mathbf{F}$, red) and REG1 $\alpha(\mathbf{E}, \mathbf{F}$, green) largely overlap. G: A light microscopy image of the same thick section stained with toluidine blue (TB) after microscopy observation of fluorescence immunostaining (A-C). The diffuse islet is composed of a mass of endocrine cells in contact with adjacent exocrine acinar-like cell clusters without a clear capsule (red arrowheads). H: Superimposed image of $(\mathbf{C})$ and $(\mathbf{G})$. I: An electron microscopy image of the black-boxed area shown in (G) obtained from a serial ultrathin section demonstrating the ultrastructural features of insulin- and glucagon-positive endocrine cells in a diffuse pancreatic islet. The diffuse islet is composed of a mass of endocrine cells interspersed between adjacent exocrine acinar-like cell clusters without a clear capsule (red arrowheads). J: An electron microscopy montage showing a pancreatic islet corresponding to the rectangle of TB staining shown in (G). Endoplasmic reticulum and Golgi apparatus are indicated by blue and red arrowheads, respectively. K: A higher magnification image of the respective boxed area in ( $\mathbf{J})$ illustrating an $\alpha$ cell containing $\alpha$-cell granules (red arrowheads) in contact with a $\beta$ cell containing $\beta$-cell granules (blue arrowheads) and condensing small vacuoles (cyan arrowheads). L: A higher magnification image of the respective boxed area in (J) illustrating a $\beta$ cell with $\beta$-cell granules (blue arrowheads) and spherical and smaller granules with small halo (green arrowheads) in contact with an $\alpha$ cell containing $\alpha$-cell granules (red arrowheads). M: A higher magnification image of the respective boxed area in ( $\mathbf{J})$ illustrating a $\beta$ cell with $\beta$-cell granules (blue arrowheads) and a zymogen-like granule (yellow arrow) in cell-to-cell contact with an exocrine acinar-like cell containing zymogen-like granules. N: Interdigitation of cell membranes (white arrows) containing $\beta$-cell granules (blue arrowheads) and 200-500-nm condensing vacuoles (cyan arrowheads) between two $\beta$ cells. Bars $=50 \mu \mathrm{m}(\mathbf{A}, \mathbf{D}, \mathbf{G}) ; 5 \mu \mathrm{m}(\mathbf{I}) ; 2 \mu \mathrm{m}(\mathbf{J}) ; 500 \mathrm{~nm}(\mathbf{K}, \mathbf{N}) ; 1 \mu \mathrm{m}(\mathbf{L}, \mathbf{M})$. 

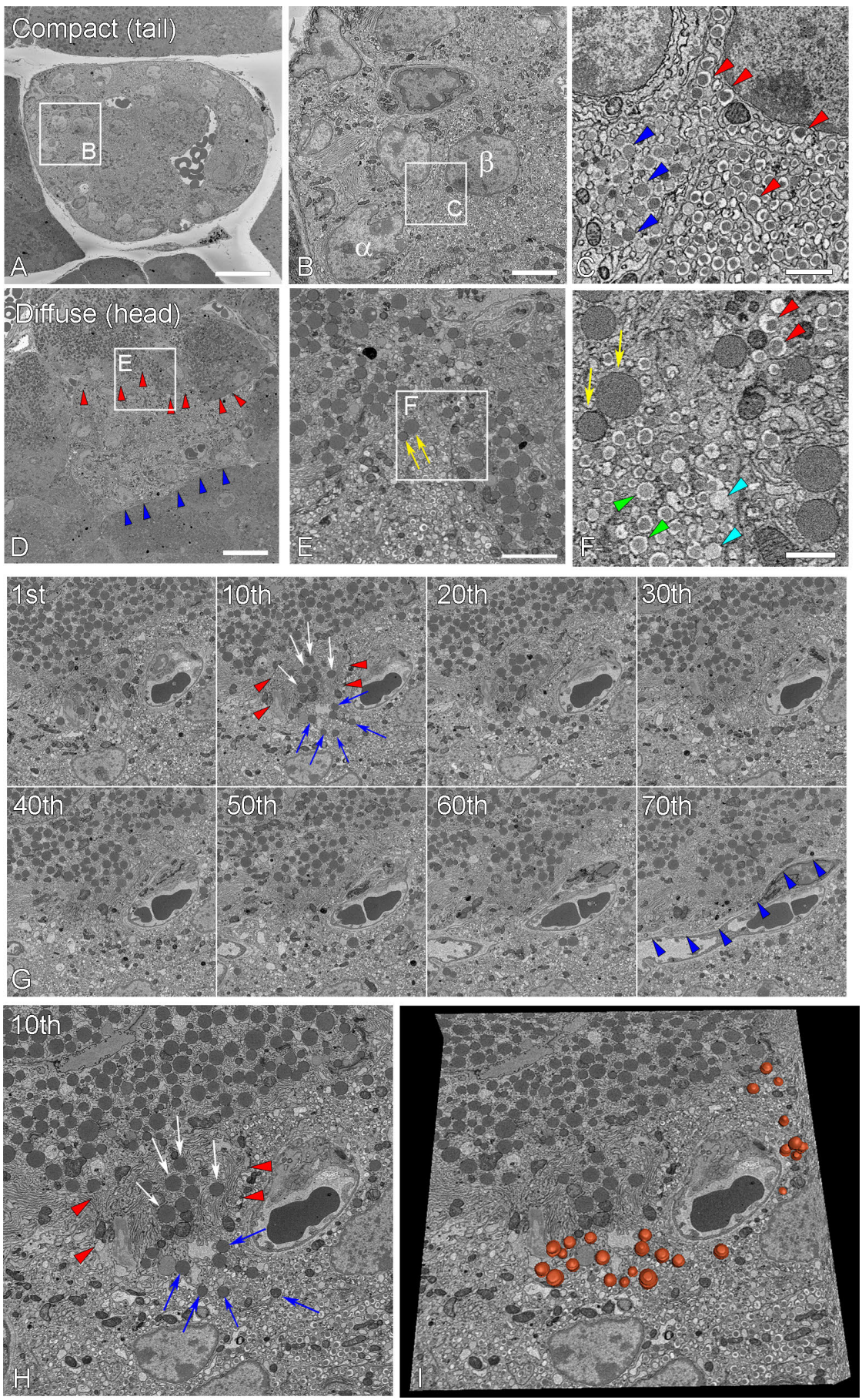

Fig. 7. Serial block-face scanning electron microscopy (SBF-SEM) observations of compact and diffuse islets from pancreatic tissues of a C57BL/6J mouse. A: The compact islet is composed of a mass of endocrine cells with a clear capsule from the tail portion of the pancreas. B: $\alpha$ cells and $\beta$ cells localized in the corner of an islet in contact with a capsule. C: $\alpha$-cell granules (blue arrowheads) are electron dense without a core, while $\beta$-cell granules (red arrowheads) show angular-shaped cores with a clear halo. D-E: The diffuse islet is composed of a mass of endocrine cells in contact with adjacent exocrine acinar-like cell clusters (ATLANTIS) (red arrowheads) without a clear capsule (blue arrowheads). F: The islet endocrine cells contain three type of granules: 1) spherical smaller granules with a small halo (green arrowheads), 2) slightly electron opaque but spherical granules without a halo having a similar size to $\alpha$-cell granules (cyan arrowheads), and 3) granules with zymogen-like granules (yellow arrows). The ATLANTIS containing $\beta$ cell granules (red arrowheads). G: Montage picture of the islet endocrine cells and ATLANTIS in the diffuse islet (D) showing every 10 serial images of a total of 70 images at 50-nm thickness each. The ATLANTIS containing zymogen-like granules (G10th, white arrows), isotopically localized to the islet cells (G10th, blue arrows), and in direct contact with endocrine cells with lamellar endoplasmic reticuli (G10th, red arrowheads). Islet cells are partially separated from the acinar-like cell clusters with connective tissues by blood vessels (G70th, blue arrowheads). H: Magnified image of (G10th). I: Three-dimensional reconstruction of serial images indicating the zymogen-like granules (shown in orange) inside the islet endocrine cells in contact with ATLANTIS. 
assays. There have been attempts to improve immunolabelling of epoxy sections by etching hydrophobic Epoxy resin with different alkali solutions [26], retrieving antigenicity by sodium metaperiodate [3, 33], protease treatments [18], or heating (autoclaving or microwaving) thick or ultrathinsections for immunoelectron microscopy with various salt solutions $[15,25,37,47,49]$. In the present study, in addition to etching the hydrophobic Epon, we utilised autoclaving and pre-treatment with hydrogen peroxide to enhance endocrine peptide immunoreactivity. It is believed that heating treatment retrieves immunoreactivity of masked antigens by exposing epitopes hidden because of crosslinking with aldehyde fixatives, whereas hydrogen peroxide treatment may increase immunoreactivity by reducing osmification of the target molecules [15, 47]. These pretreatments of Epon section are broadly applied to antibodies of immunohistochemistry not only for peptide hormones but also for several organelle markers; mitochondria, lysosome and peroxisome or membrane proteins (aquaporin-1,-2 and megalin), or soluble proteins; immunoglobulins (IgA and Ig kappa light chain), J-chain, and albumin $[18,37,49]$. Overall, we demonstrated that a combination of double fixation, embedding in Epon, and immunohistochemistry with effective pre-treatments was a very useful and robust approach for the simultaneous examination of cellular ultrastructure and antigen distribution in individual cells of human pancreas. Points to be aware of regarding to pit-fall or the limitations of this method: (i) careful select for combination of first antibodies in double fluorescent immunostaining, matching for the pretreatments conditions (heating or de-osmification), (ii) weaker DAPI staining for nucleus fluorescence staining after autoclaving.

Correlative light and electron microscopy observations revealed various types of secretory granules in individual endocrine cells of compact and diffuse islets from specimens of human pancreas (Figs. 4 and 6). Some endocrine cells of compact islets exhibited weak immunostaining for glucagon, and two types of round granules - with high and low electron densities - were observed in the same glucagon-positive cells identified in the corresponding areas of serial sections (Fig. 4). During development and diabetogenesis, $\alpha$ cells may transdifferentiate into $\beta$ cells for islet regeneration $[4,48]$. Granules with a low electron density contain glucagon, glucagon-like peptide (GLP)-1, intervening peptide 2, GLP-2, and preproglucagon, are considered to be undergoing post-translational processing because preproglucagon-containing granules are typically revealed as large alpha cell granules with a lower electron intensity $[28,36,41]$. In addition, some of the round granules with a low electron density may correspond to $\delta$-cell granules, whose sizes are smaller than those of $\alpha$ cell granules [34]. We consider that these $\delta$-cell-like granules, which contain somatostatin, would potentially inhibit insulin and glucose secretion, express autocrine or paracrine to somatostatin receptors (SSTRs), and interact with the architecture of the islet $[7,8]$.
Correlative light and electron microscopy analyses of serial thick and ultrathin sections showed intracellular organelles and membrane interdigitations near cell-cell contact areas as well as typical $\alpha$ or $\beta$-cell granules in individual insulin- and glucagon-positive endocrine cells located in both compact and diffuse islets (Figs. 4 and 6). Human Langerhans islets contain polygonal endocrine cells that are demarcated by intercellular structures, such as tight junctions, gap junctions, and membrane structures, including interdigitations and invaginations [32]. In diffuse Langerhans islets, we found that some endocrine cells appear to have direct cell-to-cell contacts with adjacent endocrine and exocrine acinar-like cells (Fig. 6). These results indicate that electric or metabolic coupling exists not only between adjacent endocrine cells, but also between endocrine cells and the surrounding pancreatic exocrine acinarlike cell clusters $[1,32]$. We also identified insulin and REG1 $\alpha$ double-positive cells that contained zymogen-like condensing granules in the endocrine islet cells, with several types of granules morphologically classified as $\beta-, \delta$, and PP-cell like granules (Fig. 6). Using serial imaging of SBF-SEM provides a highly spatial resolution of the ultrastructure of diffuse islets from the head portion of mouse pancreas, which has a ventral origin [30, 35]. Electron microscopic observations showed the same architecture in human diffuse islets in contact with acinar-like cells without a clear capsule. The typical diffuse endocrine islet in contact with acinar-like cells showed typical features of being rich in PP with a paucity of glucagon $[8,38]$. Further, endocrine islet cells colocalized most of the PP-cell-like granules and zymogen-like granules directly through cellcell contact sites with lamellar ERs, even if zymogen-like granules were excreted from the ATLANTIS. Using the correlative light and electron microscopy imaging described in the present study, additional basic and clinical studies for the precise identification of the observed granules in glucagon- and insulin-positive cells as well as the immunohistochemical detection of peptide components in human Langerhans islets for detailed clinical analyses of diabetes mellitus and chronic kidney or intestinal diseases closely related to metabolic disorders warrant further investigation [1, 4, 9, 11-14, 20, 22, 27, 49].

Interestingly, recently developed super-resolution imaging enables a detailed analysis distribution of biological molecules at an even higher resolution (e.g., a lateral resolution of 20-50 nm) by stochastic optical reconstruction microscopy when it is combined with new light microscopy technologies for nano-level analyses, an approach which may be applied to chemically fixed and Epon-embedded specimens [19, 39, 45]. In combination with immunohistochemistry and in situ hybridization in Epon sections, the correlative microscopy observation method would be a more powerful approach capable of revealing human islet regeneration under genomic and transcriptome control such as SSTR expression in $\beta$ cells from human islets $[7,8,25]$. 


\section{Conflicts of Interest}

The authors declare that there are no conflicts of interest.

\section{Acknowledgments}

This work was supported by JSPS KAKENHI Grant Number 16K08439, and by the EM facility in National Institute for Physiological Sciences in Japan. We would like to thank Editage (www.editage.jp) for English language editing.

\section{References}

1. Aida, K., Saitoh, S., Nishida, Y., Yokota, S., Ohno, S., Mao, X., Akiyama, D., Tanaka, S., Awata, T., Shimada, A., Oikawa, Y., Shimura, H., Furuya, F., Takizawa, S., Ichijo, M., Ichijo, S., Itakura, J., Fujii, H., Hashiguchi, A., Takasawa, S., Endo, T. and Kobayashi, T. (2014) Distinct cell clusters touching islet cells induce islet cell replication in association with over-expression of Regenerating Gene (REG) protein in fulminant type 1 diabetes. PLoS One 9; e95110.

2. Baskin, D. G., Erlandsen, S. L. and Parsons, J. A. (1979) Immunocytochemistry with osmium-feed tissue. 1. Light microscopic localization of growth hormone and prolactin with the unlabeled antibody-enzyme method. J. Histochem. Cytochem. $27 ; 867-872$.

3. Bendayan, M. and Zollinger, M. (1983) Ultrastructural localization of antigenic sites on osmium-fixed tissues applying the protein A-gold technique. J. Histochem. Cytochem. 31; 101109.

4. Ben-Othman, N., Vieira, A., Courtney, M., Record, F., Gjernes, E., Avolio, F., Hadzic, B., Druelle, N., Napolitano, T., NavarroSanz, S., Silvano, S., Al-Hasani, K., Pfeifer, A., Lacas-Gervais, S., Leuckx, G., Marroquí, L., Thévenet, J., Madsen, O. D., Eizirik, D. L., Heimberg, H., Kerr-Conte, J., Pattou, F., Mansouri, A. and Collombat, P. (2017) Long-term GABA administration induces alpha cell-mediated beta-like cell neogenesis. Cell 168; 73-85.

5. Bensley, R. R. (1911) Studies on the pancreas of the guinea pig. Am. J. Anat. 12; 297-388.

6. Bonner-Weir, S. and Smith, F. E. (1994) Islets of Langerhans: morphology and its implications. In: "Joslin's Diabetes Mellitus", ed. by C. R. Kahn and G. C. Weir, 13th ed., Lea \& Febiger, Philadelphia, pp. 15-28.

7. Braun, M. (2014) The somatostatin receptor in human pancreatic b-cells. Vitam. Horm. 95; 165-193.

8. Brereton, M. F., Vergari, E., Zhang, Q. and Clark, A. (2015) Alpha-, delta- and PP-cells: Are they the architectural cornerstones of islet structure and co-ordination? J. Histochem. Cytochem. 63; 575-591.

9. Briant, L., Salehi, A., Vergari, E., Zhang, Q. and Rorsman, P. (2016) Glucagon secretion from pancreatic a-cells. Ups. J. Med. Sci. 121; 113-119.

10. Brissova, M., Fowler, M. J., Nicholson, W. E., Chu, A., Hirshberg, B., Harlan, D. M. and Powers, A. C. (2005) Assessment of human pancreatic islet architecture and composition by laser scanning confocal microscopy. $J$. Histochem. Cytochem. 53; 1087-1097.

11. Bruneval, P., Hinglais, N., Alhenc-Gelas, F., Tricottet, V., Corvol, P., Menard, J., Camilleri, J. P. and Bariety, J. (1986) Angiotensin
I converting enzyme in human intestine and kidney. Ultrastructural immunohistochemical localization. Histochemistry 85; 73-80.

12. Buffa, R., Polak, J. M., Pearse, A. G., Solcia, E., Grimelius, L. and Capella, C. (1975) Identification of the intestinal cell storing gastric inhibitory peptide. Histochemistry 43; 249-255.

13. Calderari, S., Irminger, J. C., Giroix, M. H., Ehses, J. A., Gangnerau, M. N., Coulaud, J., Rickenbach. K., Gauguier, D., Halban, P., Serradas, P. and Homo-Delarche, F. (2014) Regenerating 1 and $3 \mathrm{~b}$ gene expression in the pancreas of type 2 diabetic Goto-Kakizaki (GK) rats. PLoS One 9; e90045.

14. Cnop, M., Hughes, S. J., Igoillo-Esteve, M., Hoppa, M. B., Sayyed, F., van de Laar, L., Gunter, J. H., de Koning, E. J., Walls, G. V., Gray, D. W., Johnson, P. R., Hansen, B. C., Morris, J. F., Pipeleers-Marichal, M., Cnop, I. and Clark, A. (2010) The long lifespan and low turnover of human islet beta cells estimated by mathematical modelling of lipofuscin accumulation. Diabetologia 53; 321-330.

15. D'Amico, F., Skarmoutsou, E. and Stivala, F. (2009) State of the art in antigen retrieval for immunohistochemistry. J. Immunol. Methods 341; 1-18.

16. Dewitt, L. M. (1906) Morphology and physiology of areas of Langerhans in some vertebrates. J. Exp. Med. 8; 193-239.

17. Grube, D. and Bohn, R. (1983) The microanatomy of human islets of Langerhans, with special reference to somatostatin (D-) cells. Arch. Histol. Jpn. 46; 327-353.

18. Haraguchi, C. M. and Yokota, S. (2002) Immunofluorescence technique for 100-nm-thick semithin sections of Epon-embedded tissues. Histochem. Cell Biol. 117; 81-85.

19. Huang, B., Wang, W., Bates, M. and Zhuang, X. (2008) Threedimensional super-resolution imaging by stochastic optical reconstruction microscopy. Science 319; 810-813.

20. Jonsson, A., Ladenvall, C., Ahluwalia, T. S., Kravic, J., Krus, U., Taneera, J., Isomaa, B., Tuomi, T., Renström, E., Groop, L. and Lyssenko, V. (2013) Effects of common genetic variants associated with type 2 diabetes and glycemic traits on $\alpha$ - and $\beta$ cell function and insulin action in humans. Diabetes 62; 29782983.

21. Kaung, H. C. (1985) Glucagon and pancreatic polypeptide immunoreactivities co-exist in a population of rat islet cells. Experientia 41; 86-88.

22. Klöppel, G. and Lenzen, S. (1984) Anatomy and physiology of the endocrine pancreas. In: "Pancreatic Pathology", ed. by G. Klöppel and P. U. Heitz, Churchill Livingstone, London, pp. 133-153.

23. Lacy, P. E. (1957) Electron microscopic identification of different cell types in the islets of Langerhans of the guinea pig, rat, rabbit and dog. Anat. Rec. 128; 255-267.

24. Lumelsky, N., Blondel, O., Laeng, P., Velasco, I., Ravin, R. and McKay, R. (2001) Differentiation of embryonic stem cells to insulin-secreting structures similar to pancreatic islets. Science 292; 1389-1394.

25. Matsui, T., Onouchi, T., Shiogama, K., Mizutani, Y., Inada, K., Fuxun, Y., Hayasaka, D., Morita, K., Ogawa, H., Mahara, F. and Tsutsumi, Y. (2015) Coated glass slides TACAS are applicable to heat-assisted immunostaining and in situ hybridization at the electron microscopy level. Acta Histochem. Cytochem. 48; 153 157.

26. Maxwell, M. H. (1978) Two rapid and simple methods used for the removal of resins from 1.0 micron thick epoxy sections. $J$ Microsc. 112; 253-255.

27. Mills, S. E. (2012) Histology for Pathologists, 4th ed., Wolters Kluwer Health/Lippincott Williams \& Wilkins, Philadelphia, pp. 777-816.

28. Mojsov, S., Heinrich, G., Wilson, I. B., Ravazzola, M., Orci, L. 
and Habener, J. F. (1986) Preproglucagon gene expression in pancreas and intestine diversifies at the level of post-translational processing. J. Biol. Chem. 261; 11880-11889.

29. Nakai, Y. and Iwashita, T. (1976) Correlative light and electron microscopy of the frog adrenal gland cells using adjacent Eponembedded sections. Arch. Histol. Jpn. 39; 183-191.

30. Nguyen, H. B., Thai, T. Q., Saitoh, S., Wu, B., Saitoh, Y., Shimo, S., Fujitani, H., Otobe, H. and Ohno, N. (2016) Conductive resins improve charging and resolution of acquired images in electron microscopic volume imaging. Sci. Rep. 6; 23721.

31. Oikawa, T., Ogawa, K. and Taniguchi, K. (1992) Immunocytochemical studies on the pancreatic endocrine cells in the Japanese newt (Cynopus pyrrhogaster). Exp. Anim. 41; 505-514.

32. Orci, L., Malaisse-Lagae, F., Amherdt, M., Ravazzola, M., Weisswange, A., Dobbs, R., Perrelet, A. and Unger, R. (1975) Cell contacts in human islets of Langerhans. J. Clin. Endocrinol. Metab. 41; 841-844.

33. Ozawa, H., Picart, R., Barret, A. and Tougard, C. (1994) Heterogeneity in the pattern of distribution of the specific hormonal product and secretogranins within the secretory granules of rat prolactin cells. J. Histochem. Cytochem. 42; 1097-1107.

34. Pelletier, G. (1977) Identification of four cell types in the human endocrine pancreas by immunoelectron microscopy. Diabetes 26; 749-756.

35. Pfeifer, C. R., Shomorony, A., Aronova, M. A., Zhang, G., Cai, T., Xu, H., Notkins, A. L. and Leapman, R. D. (2015) Quantitative analysis of mouse pancreatic islet architecture by serial block-face SEM. J. Struct. Biol. 189; 44-52.

36. Ravazzola, M., Perrelet, A., Unger, R. H. and Orci, L. (1984) Immunocytochemical characterization of secretory granule maturation in pancreatic A-cells. Endocrinology 114; 481-485.

37. Shimo, S., Saitoh, S., Saitoh, Y., Ohno, N. and Ohno, S. (2015) Morphological and immunohistochemical analyses of soluble proteins in mucous membranes of living mouse intestines by cryotechniques. Microscopy (Oxf). 64; 189-203.

38. Suda, K., Mizuguchi, K. and Hoshino, A. (1981) Differences of the ventral and dorsal anlagen of pancreas after fusion. Acta Pathol. Jpn. 31; 583-599.

39. Suleiman, H., Zhang, L., Roth, R., Heuser, J. E., Miner, J. H., Shaw, A. S. and Dani, A. (2013) Nanoscale protein architecture of the kidney glomerular basement membrane. Elife 2; e01149.

40. Terazono, K., Uchiyama, Y., Ide, M., Watanabe, T., Yonekura,
H., Yamamoto, H. and Okamoto H. (1990) Expression of reg protein in rat regenerating islets and its co-localization with insulin in the beta cell secretory granules. Diabetologia $33 ; 250$ 252.

41. Varndell, I. M., Bishop, A. E., Sikri, K. L., Uttenthal, L. O., Bloom, S. R. and Polak, J. M. (1985) Localization of glucagonlike peptide (GLP) immunoreactants in human gut and pancreas using light and electron microscopic immunocytochemistry. $J$. Histochem. Cytochem. 33; 1080-1086.

42. Watanabe, T., Yonekura, H., Terazono, K., Yamamoto, H. and Okamoto, H. (1990) Complete nucleotide sequence of human reg gene and its expression in normal and tumoral tissues. The reg protein, pancreatic stone protein, and pancreatic thread protein are one and the same product of the gene. J. Biol. Chem. 265; $7432-7439$.

43. Watari, N., Tsukagoshi, N. and Honma, Y. (1970) Correlative light and electron microscopy of the islets of Langerhans in some lower vertebrates. Arch. Histol. Jpn. 31; 371-392.

44. Wittingen, J. and Frey, C. F. (1974) Islet concentration in the head, body, tail and uncinate process of the pancreas. Ann. Surg. $179 ; 412-414$

45. Wu, M., Huang, B., Graham, M., Raimondi, A., Heuser, J. E., Zhuang, X. and De Camilli, P. (2010) Coupling between clathrindependent endocytic budding and F-BAR-dependent tubulation in a cell-free system. Nat. Cell Biol. 12; 902-908.

46. Xu, W., Li, W., Wang, Y., Zha, M., Yao, H., Jones, P. M. and Sun, Z. (2015) Regenerating islet-derived protein 1 inhibits the activation of islet stellate cells isolated from diabetic mice. Oncotarget 6; 37054-37065.

47. Yamashita, S. and Okada, Y. (2014) Heat-induced antigen retrieval in conventionally processed Epon-embedded specimens: procedures and mechanisms. J. Histochem. Cytochem. 62; 584-597.

48. Ye, L., Robertson, M. A., Hesselson, D., Stainier, D. Y. and Anderson, R. M. (2015) Glucagon is essential for alpha cell transdifferentiation and beta cell neogenesis. Development 142; 1407-1417.

49. Zhai, X. Y., Kristoffersen, I. B. and Christensen, E. I. (2007) Immunocytochemistry of renal membrane proteins on epoxy sections. Kidney Int. 72; 731-735.

This is an open access article distributed under the Creative Commons Attribution License, which permits unrestricted use, distribution, and reproduction in any medium, provided the original work is properly cited. 